\title{
Hacia una ontología social del cuerpo en Butler: análisis y límites
}

\author{
Asunción OLIVA PORTOLÉS \\ Instituto de Investigaciones Feministas de la U.C.M. \\ mariasuncion75@gmail.com
}

Recibido: Mayo 2015

Aceptado: Junio 2015

\section{RESUMEN}

Este artículo analiza la pervivencia histórica del dualismo platónico alma-cuerpo y el momento histórico en que fue superado, posibilitando el análisis de la concepción del cuerpo libre ya de su contraposición con el alma o la mente. Michel Foucault y las teóricas feministas del siglo XX que efectuaron la crítica a un sujeto sin "carne”, consiguieron modificar la perspectiva de lo corporal. Entre todas las teóricas feministas que han tratado el cuerpo he escogido a Butler quien, en mi opinión, supera las concepciones de D. Haraway y R. Braidotti sobre esta cuestión. Esta autora, no sin elementos discutibles, ha ido elaborando a lo largo de su obra una teoría que ella denomina "ontología social del cuerpo". Sin embargo, uno de los elementos que me parece más problemático en Butler es el alto grado de abstracción de sus propuestas y la desafortunada crítica al concepto de patriarcado. Por ello al final lo contrasto con otros planteamientos como los de Mohanty y Eisenstein, y sobre todo, los de Celia Amorós, que me parecen más cercanos a las necesidades de un feminismo en la era de la globalización.

Palabras clave: Cuerpo, poder, performatividad, precaridad, patriarcado.

\section{Towards a social ontology of the body in Butler: analysis and limits.}

\begin{abstract}
This article analyzes the historical survival of Platonic soul-body dualism and the historical moment in which it was overcome, allowing the analysis of the concept of the body without its opposition with the soul or mind. Michel Foucault and the feminist theories of the twentieth century who made the criticism of a subject without "flesh", disembodied, managed to change the perspective of the body. Between feminist theories that have tried the body, I have chosen the work of J. Butler who, in my opinion, surpasses other conceptions such as the thought of D. Haraway and R. Braidotti on this issue. This author, not without questionable elements, has developed throughout his work a theory she calls "a social ontology of the body". However, the element that I find most problematic in Butler is the high degree of abstraction of their proposals and the unfortunate criticism of the concept of patriarchy. So, I put it as opposed to other approaches, such as the ideas of Mohanty and Eisenstein, and particularly the ideas of C. Amorós, that seem to me closer to the needs of feminism in the age of globalization.
\end{abstract}

Keywords: Body, power, performativity, precarity, patriarchy. 


\section{INTRODUCCIÓN}

Para abordar un tema tan complejo como lo es el de "Cuerpo, Feminismo y Filosofía”, me parece imprescindible el análisis de la pervivencia histórica del dualismo platónico alma-cuerpo y en qué momento ha sido abiertamente superado, haciendo posible analizar la concepción del cuerpo, libre ya de su contraposición con el alma o la mente. Como Susan Bordo explicó detalladamente en su libro de 1987 The Flight to Objectivity, Platón consideró al cuerpo como un obstáculo para el alma, aunque esté entretejido con ella. Quizá en el diálogo Fedón es donde se percibe más claramente esta concepción, y se repite la idea del cuerpo como cárcel o tumba del alma, visión que sigue en San Agustín y que culmina en Descartes, quien verá la sustancia corpórea y la sustancia espiritual totalmente diferentes, ya que se definen la una por oposición a la otra. La res extensa en el hombre queda separada de la res cogitans y la interacción entre ellas se vuelve, por lo menos, problemática. Para Bordo, el dualismo mente/cuerpo no es una mera posición filosófica sino más bien una metafísica práctica que se ha instalado socialmente en la medicina, el derecho, las representaciones artísticas y literarias, la construcción psicológica del ser, las relaciones interpersonales, la cultura popular y la publicidad (Bordo, 1994: 30) Como dice esta autora, esta dualidad ha continuado en la de naturaleza/cultura:

"El cuerpo es ubicado en el lado de la naturaleza dentro de la división naturaleza/cultura. Como tal, se le concibe como relativamente no cambiante en sus aspectos más básicos y unitarios. Es decir, hablamos del "Cuerpo" como hablamos de la "Razón" o de la "Mente", como si un modelo fuese igualmente descriptivo y preciso de toda la experiencia corporal humana, sin importar el sexo, la raza, la edad o cualquier otro atributo personal. Se asume que ese modelo es una suerte de núcleo neutral y genérico.

\section{EL CUERPO, LA CARNE Y EL ALMA EN FOUCAULT}

Aunque Bordo habla de un cambio de paradigma y piensa en Marx como el primer filósofo que tiene una nueva visión del cuerpo, en mi opinión es Nietzsche el primero que sugiere esta nueva concepción de lo corporal. Ya en el siglo XX, M. Foucault sigue los pasos de Nietzsche y rompe definitivamente con este dualismo. En Las palabras y las cosas al hablar del paso de la "episteme" clásica a la moderna (principios del siglo XIX), cuando se forman las "ciencias humanas”, habla del hombre como "un extraño duplicado empírico-trascendental, ya que es un ser tal que en él se construirá conocimiento de aquello que hace posible todo conocimiento.”

La experiencia del hombre se da en "un cuerpo que es su cuerpo fragmento de espacio ambiguo, cuya espacialidad propia e irreductible se articula, sin embargo, sobre el espacio de las cosas”. En esta experiencia, el deseo se da como apetito primordial a partir del cual toman 
valor todas las cosas; para esta misma experiencia, se aplica un lenguaje al filo del cual pueden darse todos los discursos de todos los tiempos, todas las sucesiones y todas las simultaneidades (...) El modo de ser de la vida y aquello mismo que hace que la vida no exista sin prescribirme sus formas, me son dados, fundamentalmente, por mi cuerpo. En el fondo de todas las positividades empíricas y de aquello que puede señalarse como limitaciones concretas en la existencia del hombre, se descubre una finitud - que en cierto sentido es la misma: está marcada por la espacialidad del cuerpo, por el hueco del deseo y el tiempo del lenguaje. (Foucault 1968:308-310)

Espacialidad, deseo y lenguaje son, por tanto, los límites de la finitud del cuerpo. Pero en Vigilar y Castigar es cuando la ruptura de este dualismo se produce claramente.

"La historia de esta "microfísica" del poder punitivo sería entonces una genealogía o una pieza para una genealogía del "alma" moderna. Más que ver en esta alma los restos reactivados de una ideología, habría que reconocer en ella más bien el correlato actual de cierta tecnología del poder sobre el cuerpo. No se debería decir que el alma es una ilusión, o un efecto ideológico. Pero sí que existe, que tiene una realidad, que está producida permanentemente en torno, en la superficie y en el interior del cuerpo por el funcionamiento de un poder que se ejerce sobre aquellos a quienes se castiga, de una manera más general sobre aquellos a quienes se vigila, se educa y corrige, sobre aquellos a quienes se sujeta a un aparato de producción y se controla a lo largo de toda su existencia. (...) Esta alma real e incorpórea no es en absoluto sustancia; es el elemento en el que se articulan los efectos de determinado tipo de poder y la referencia de un saber, el engranaje por el cual las relaciones de saber dan lugar a un saber posible, y el saber prolonga y refuerza los efectos del poder(...) Pero no hay que engañarse: no se ha sustituido el alma, ilusión de los teólogos, por un hombre real, objeto de saber, de reflexión filosófica o de intervención técnica. El hombre de que se nos habla y que se nos invita a liberar es ya en sí el efecto de un sometimiento mucho más profundo que él mismo. Un "alma" lo habita y lo conduce a la existencia, que es una pieza en el dominio que el poder ejerce sobre el cuerpo. El alma, efecto e instrumento de una anatomía política; el alma, prisión del cuerpo”. (Foucault, 1976: 36) ${ }^{1}$

El alma no es una sustancia sino que está producida continuamente por la retícula

${ }^{1}$ Si he reproducido una cita tan larga es porque me parece muy significativa. 
del poder/saber que permea todo lo que somos. La frase platónica se ha invertido: el alma es prisión del cuerpo, es decir lo que configura al cuerpo y hace posible que el poder penetre en él. Ya en el capítulo final del primer volumen de su Historia de la sexualidad (Foucault, 1977), el autor señala la necesidad de hacer una "historia de los cuerpos" que indague "la manera en que se los invistió de lo más material y vital que hay en ellos". En esta obra da la impresión de que para Foucault, el cuerpo tiene una materialidad que es ontológicamente distinta de las relaciones de poder que consideran a ese cuerpo como un lugar en el que se inscriben. Sin embargo, en Vigilar y castigar (Foucault, 1976) nos ha ofrecido, como hemos visto en la cita anterior, una configuración diferente de la relación entre materialidad e investidura. El alma aparece como un instrumento de poder a través del cual se cultiva y se forma el cuerpo. Por tanto, esta operación produce los sujetos que sujeta; es decir, los sujeta en y a través de las relaciones preceptivas de poder que obran como su principio formativo. El alma sería entonces una realidad histórica, como producto del funcionamiento del poder que se ejerce sobre aquellos a quienes se castiga, se vigila o que están sujetos a un aparato de producción y son controlados a lo largo de toda su existencia. El alma está inscrita en el cuerpo y no tiene carácter atemporal, natural ni universal. No es una sustancia, al modo de Spinoza, sino algo que podemos llamar corporeidad, lo único que existe, rompiendo no solo con el dualismo alma-cuerpo, materia-espíritu sino también con el de interior-exterior.

Creo que sería interesante apuntar, aunque solo sea, la diferencia que existe en Foucault entre cuerpo y carne, sobre todo cuando sabemos que los escritos inéditos, cuyo título sería Las Confesiones de la Carne (Aveux de la chair), el cuarto tomo de la Historia de la sexualidad, es decir, el proyecto que Foucault dejó inacabado al morir en 1984, han sido comprados por el Estado francés a sus herederos en 2013 y pensamos que serán publicados algún día. Por lo que se refiere a la "carne” y aunque Foucault era reacio a dar definiciones, podemos citar el primer volumen de Historia de la sexualidad. La voluntad de saber:

"De este modo, allí donde la Edad Media había organizado un discurso unitario acerca de la carne, encontraremos más tarde una discursividad dispersa, múltiple: la demografía, la biología, la medicina, la psiquiatría, la psicología, la moral, la pedagogía, la crítica política. [...] (L) a tecnología del sexo, en lo esencial, se ordenará, a partir de este momento, respecto a la institución médica, respecto a la exigencia de normalidad, y, más que respecto de la cuestión de la muerte y del castigo eterno, respecto al problema de la vida y de la enfermedad. La 'carne' es rebajada al organismo.” (Foucault, 1977: 154-155)

Es decir, en el pensamiento griego el cuerpo fue objeto de reflexión. ”Todo lo que concierne al uso de los placeres no se pueda pensar sin pensar el cuerpo." El uso de la expresión "aphrodisia" implica la imposibilidad de aplicar otros conceptos y experiencias a dicho momento histórico (Foucault, M.:1986:39). En cambio, la carne como objeto de pensamiento aparece con el cristianismo. Y, desde el siglo XVIII las tecnologías en torno al sexo: psicoanálisis, psiquiatría, medicina y psicología, fueron 
las condiciones de posibilidad del "dispositivo" de la sexualidad. Detrás de cada una de estas nociones se encuentran experiencias distintas y dinámicas contrapuestas de modelación de la subjetividad.

\section{EL CUERPO MATERIAL EN JUDITH BUTLER: DE LA PERFOMATIVIDAD A LA PRECARIDAD}

"¿Y qué ocurre con la materialidad de los cuerpos, Judy?

Esta es la pregunta que se hace Butler en el prefacio de su libro Cuerpos que importan. Por qué utiliza ese diminutivo y en qué situación lo hace está explicado por ella misma en ese texto. Pero es una pregunta que quienes la leemos también hemos querido hacerle. La respuesta es complicada.

"Por cierto, los cuerpos viven y mueren; comen y duermen; sienten dolor y placer; soportan la enfermedad y la violencia y uno podría proclamar escépticamente que estos "hechos" no pueden descartarse como una mera construcción. Seguramente debe de haber algún tipo de necesidad que acompañe a estas experiencias primarias e irrefutables. Y seguramente la hay. Pero su carácter irrefutable en modo alguno implica qué significaría afirmarlas ni a través de qué medios discursivos. Además, ¿por qué lo construido se entiende como artificial y prescindible? ¿Qué deberíamos hacer con las construcciones sin las cuales no podríamos pensar, vivir o dar algún sentido, aquellas que de algún modo se nos hicieron necesarias? Ciertas construcciones del cuerpo, ¿'son constitutivas en el sentido de que no podríamos operar sin ellas, en el sentido de que sin ellas no habría ningún "yo" ni ningún "nosotros"? (Butler, 2003:13)

Concebir el cuerpo, pues, como algo construido exige replantearse de nuevo la significación de la construcción misma. Y si ciertas construcciones parecen constitutivas, es decir, si tienen el carácter de ser aquello sin lo cual "no podríamos siquiera pensar, podemos sugerir que los cuerpos sólo surgen, sólo perduran, sólo viven dentro de las limitaciones productivas de ciertos esquemas reguladores en alto grado generizados.”

Es decir, que es la noción de construcción la que tiene que ser escrutada. Y en este libro que, como ella misma afirma, presenta una revisión de algunas ideas expresadas en El género en disputa, no solo va a analizar la noción de construcción, sino también la de performatividad y la de materia que conceptúa como "proceso de materialización”. Esta tarea de reconsiderar y resignificar es, según la autora, imprescindible para "teorizar en las ruinas del Logos", como ella dice. Porque si suponemos que construir, p.ej., el sexo o el género, significa que para hacerlo tiene que haber una "naturaleza" corporal, que sea anterior a la inteligibilidad, sobre la que la cultura o la sociedad imprime sus rasgos, volvemos a situarnos en la metafísica de la sustancia: el cuerpo (o la materia) es una superficie natural, preexistente y pasiva. No 
es así: lo que llamamos "naturaleza" tiene una historia y no una historia meramente social. La diferencia sexual nunca es sencillamente una función de diferencias materiales que no estén de algún modo marcadas y formadas por las prácticas discursivas. Además, afirmar que las diferencias sexuales son indisociables de las demarcaciones discursivas no es lo mismo que decir que el discurso causa la diferencia sexual.

\begin{abstract}
"En este sentido pues, el "sexo" no sólo funciona como norma, sino que además es parte de una práctica reguladora que produce los cuerpos que gobierna, es decir, cuya fuerza reguladora se manifiesta como una especie de poder productivo, el poder de producir -demarcar, circunscribir, diferenciar los cuerpos que controla. De modo tal que el "sexo" es un ideal regulatorio cuya materialización se impone y se logra (o no) mediante ciertas prácticas sumamente reguladas.” (Butler, 2003:15)
\end{abstract}

Tanto en El género en disputa, como en este libro, Butler insiste que las normas se reiteran. Pero esta repetición, nunca idéntica a sí misma, debe ser repetición de algo: de gestos, de actitudes, de palabras, de movimientos (acordes con las normas)...que surgen ¿dónde? Parece que en el cuerpo. Ahora bien, es cierto que la corporeidad material no puede entenderse como algo subyacente que no cambia, porque sabemos que el cuerpo (y la materia) está continuamente transformándose, es decir, "en proceso". Así, "poner en tela de juicio un supuesto no equivale a desecharlo; antes bien, implica liberarlo de su encierro metafísico para poder comprender qué intereses se afirman en el -en virtud de esa locación metafísica-, y permitir, en consecuencia, que el término ocupe otros espacios y sirva a objetivos políticos muy diferentes.”

Y eso ocurre con la materia (y con el cuerpo). Butler pone un ejemplo paralelo: hablar de las mujeres no supone que ese universal no sea puesto en cuestión. Aquí Butler se refiere a la noción de "problematización" que aparece ya en Foucault (Foucault 1991:231-232) ${ }^{2}$. Pues bien, los cuerpos “materiales" son siempre sexuados para Butler. Por tanto el cuerpo es analizado desde el punto de vista de su inscripción sexual, una norma cultural que gobierna la materialización de los cuerpos. Y allí mismo es donde surge la dinámica del poder y las normas reguladoras que "gobiernan su materialización”. Allí también surge la performatividad como poder de reiteración del discurso para producir "los fenómenos que regula e impone". Y como resultado de todo ello tiene lugar la construcción del "sexo", no como algo que un sujeto

${ }^{2}$ En una entrevista, "El interés por la verdad”, recogida en el volumen Saber y Verdad, Foucault aborda el concepto de "problematización" "Problematización no quiere decir representación de un objeto pre-existente, ni tampoco creación por medio del discurso de un objeto que no existe. Es el conjunto de las prácticas discursivas y no discursivas lo que hace entrar a algo en el juego de lo verdadero y de lo falso y lo constituye como objeto de pensamiento (ya sea bajo la forma de reflexión moral, del conocimiento científico, de análisis político, etc.) “ 
voluntariamente se da a sí mismo sino como una norma cultural que gobierna la materialización de los cuerpos y así el mismo sujeto, el "yo" hablante, se forma en virtud de pasar por ese proceso de asumir un sexo ante "los medios discursivos que emplea el imperativo heterosexual para permitir ciertas identificaciones sexuadas y excluir y repudiar otras.” Esta matriz excluyente mediante la cual se forman los sujetos requiere pues la producción simultánea de una esfera de seres ab-yectos, de aquellos que no son "sujetos", pero que forman el exterior constitutivo del campo de los sujetos.

"Lo abyecto designa aquí precisamente aquellas zonas "invivibles", "inhabitables" de la vida social que, sin embargo, están densamente pobladas por quienes no gozan de la jerarquía de los sujetos, pero cuya condición de vivir bajo el signo de lo "invivible" es necesaria para circunscribir la esfera de los sujetos.”) (Butler, 2003:19-20)

Podríamos decir, pues, que en Cuerpos que importan, Butler problematiza varios conceptos que había utilizado en El género en disputa, como el de construcción, el de performatividad y, asimismo, introduce la idea de proceso de materialización. La autora replantea el problema de la "construcción” a partir de la formación de la materia como un proceso de materialización. Lo esencial estriba entonces en que la construcción no es un acto único ni un proceso causal iniciado por un sujeto y que culmina en una serie de efectos fijados. La construcción no solo se realiza en el tiempo, sino que es en sí misma un proceso temporal que opera a través de la reiteración de normas.

\begin{abstract}
"Y aquí ya no sería adecuado decir que el término "construcción" corresponde al sitio gramatical del sujeto ni su acto, sino un proceso de reiteración mediante el cual llegan a emerger tanto los "sujetos" como los "actos". No hay ningún poder que actúe, sólo hay una actuación reiterada que se hace poder en virtud de su persistencia e inestabilidad". (Butler, 2003:28)
\end{abstract}

Ya no podemos entender el alma como algo espiritual, intangible, que reside en un cuerpo material y "natural", sino el factor (efecto e instrumento a la vez) que ejerce poder sobre el cuerpo. Y así dice Butler. "En este sentido, lo que constituye el carácter fijo del cuerpo, sus contornos, sus movimientos, será plenamente material, pero la materialidad tiene que concebirse ahora como el efecto más productivo del poder.”

"Las cuestiones que estarán en juego en tal reformulación de la materialidad de los cuerpos serán las siguientes: (1) la reconsideración de la materia de los cuerpos como el efecto de una dinámica de poder, de modo tal que la materia de los cuerpos sea indisociable de las normas reguladoras que gobiernan su materialización y la significación de aquellos efectos materiales; (2) la comprensión de la performatividad (,,,) como ese poder reiterativo del discurso para producir los fenómenos que regula e impone; (3) la construcción del "sexo", no ya como un dato 
corporal dado sobre el cual se impone artificialmente la construcción del género, sino como una norma cultural que gobierna la materialización de los cuerpos; (4) una reconsideración del proceso mediante el cual un sujeto asume, se apropia, adopta una norma corporal,(...) como una evolución en la que el sujeto, el "yo" hablante, se forma en virtud de pasar por ese proceso de asumir un sexo; y (5) una vinculación de este proceso de "asumir" un sexo con la cuestión de la identificación y con los medios discursivos que emplea el imperativo heterosexual para permitir ciertas identificaciones sexuadas y excluir y repudiar otras. Esta matriz excluyente mediante la cual se forman los sujetos requiere pues la producción simultánea de una esfera de seres abyectos, de aquellos que no son "sujetos", pero que forman el exterior constitutivo del campo de los sujetos.” (Butler, 2003:20)

El objetivo de esta cita tan larga es mostrar cómo en esta autora se entrecruzan las nociones de "construcción”, "performatividad" y "proceso de materialización”. La teoría de la performatividad de género presupone que las normas están actuando sobre nosotros antes de que tengamos la ocasión de intervenir y que, cuando actuamos, subrayamos las normas que operan sobre nosotros, tal vez de un modo nuevo o de manera inesperada, pero siempre en relación con las normas que nos preceden y que nos exceden. En otras palabras, las normas actúan sobre nosotros, trabajan sobre nosotros y debido a esta manera en la que nosotros "estamos siendo trabajados" se abren camino en nuestra propia acción. La performatividad es un proceso que implica la configuración de nuestra actuación en formas que no siempre comprendemos del todo. Pero recordemos que la performatividad no sólo se refiere a actos específicos de discurso sino también a la reproducción de normas. De hecho, no hay reproducción en el mundo social si al mismo tiempo no se reproducen aquellas normas por las que se rige la inteligibilidad del cuerpo, tanto en el espacio como en el tiempo.

"Que esta reiteración sea necesaria es una señal de que la materialización nunca es completa, de que los cuerpos nunca acatan enteramente las normas mediante las cuales se impone su materialización. En realidad, son las inestabilidades, las posibilidades de rematerialización abiertas por este proceso las que marcan un espacio en el cual la fuerza de la ley reguladora puede volverse contra sí misma y producir rearticulaciones que pongan en tela de juicio la fuerza hegemónica de esas mismas leyes reguladoras.” (Butler, 2003:18)

Para Butler, la performatividad del género no puede entenderse, pues, de modo independiente de la práctica forzada y reiterativa de los regímenes sexuales reguladores. La capacidad de acción, condicionada por los regímenes mismos del discurso/poder, no puede combinarse con el voluntarismo o el individualismo ni supone la existencia de un sujeto que escoge. El régimen de heterosexualidad tiene como objetivo circunscribir la "materialidad" del sexo y esa materialidad se forma y se sostiene a través de la materialización de las normas reguladoras que son las de la 
hegemonía heterosexual.

"Esa materialización de las normas requiere que se produzcan determinados procesos identificatorios, a través de los cuales alguien asume tales normas o se apropia de ellas y estas identificaciones preceden y permiten la formación de un sujeto, pero este no las realiza en el sentido estricto de la palabra. Así, los límites del constructivismo quedan expuestos en aquellas fronteras de la vida corporal donde los cuerpos abyectos o deslegitimados no llegan a ser considerados "cuerpos". (Butler, 2003:28)

Creo que es importante señalar que, tanto cuando habla de reconsiderar el proceso de construcción del cuerpo material, como de precisar la noción de performatividad, la autora siempre acaba en lo abyecto, en el cuerpo abyecto, en los seres abyectos. Y ello me lleva a la interpretación que la misma autora hace de este giro. En una entrevista concedida a I. Costera y B. Prins, (Costera, y Prins, 1998), Butler introduce la idea de que el poder marca los límites de la ontología:

"Me parece crucial poner de nuevo en circulación y resignificar los operadores ontológicos, aunque sea solamente para presentar la propia ontología como un campo cuestionado. Foucault ofrece otro paso, hecho posible por el tipo de trabajo que él realiza. Este tiene que ver con la indagación sobre cómo ciertos tipos de discurso producen efectos ontológicos u operan a través de la circulación de movimientos ontológicos. En parte me veo a mi misma trabajando con discursos que operan mediante exigencias ontológicas - “no hay un actor detrás del acto"- y recirculando el "hay" para producir un contra-imaginario a la metafísica dominante.”

Por tanto, la intención de Butler no es prohibir el uso de términos ontológicos sino, por el contrario, usarlos más, explorarlos y rescatarlos, abusar de ellos, para que no puedan ya hacer su trabajo habitual. Y, asimismo, la pregunta sobre por qué el dominio de la ontología es el mismo delimitado por el poder, nos aclara toda la cuestión de los cuerpos abyectos.

“¿Cómo es que algunos tipos de sujetos reclaman ontología, cómo es que ellos cuentan o se califican como reales? En ese caso, estamos hablando sobre la distribución de efectos ontológicos, que es un mecanismo de poder, instrumentalizado para fines de jerarquía y subordinación, y también con vistas a la exclusión y a la producción de dominios de lo inconcebible. Todo ese dominio de la ontología que el buen filósofo, aquel conceptualmente puro, considera obvio, ya viene profundamente corrompido desde su origen." 
Pero las cosas cambian cuando el filósofo, en este caso Butler, quiere introducir deliberadamente, una contradicción performativa:

“Lo que yo podría decir es que "hay cuerpos abyectos”, y eso podría ser un performativo al cual doto de ontología. Yo doto de ontología exactamente a aquello que ha sido sistemáticamente privado del privilegio de la ontología. El dominio de la ontología es un dominio regulado: lo que se produce dentro de él, lo que es excluido de él para que el dominio se constituya como tal, es un efecto del poder. Y lo performativo puede ser una de las formas por las cuales el discurso se hace operativo debido al poder. Así, estoy realizando (performing) una contradicción performativa, a propósito. Y estoy haciendo eso exactamente para confundir al filósofo conceptualmente correcto y para plantear la cuestión de la condición secundaria y derivativa de la ontología. Se trata claramente de inaugurar un nuevo dominio ontológico, no de presuponer uno que ya exista. Se trata de instituir discursivamente ese dominio.

Es decir, la frase "hay cuerpos abyectos" no es una constatación ni una consecuencia, es una operación reiterativa que Butler "realiza" para dinamitar desde dentro la ontología al uso, instituyendo discursivamente un nuevo dominio ontológico. Por tanto, sobre este planteamiento de lo que define quién es considerado sujeto y quién no, es como la performatividad se vincula con la precaridad. La performatividad de género está completamente relacionada con quién es considerado a efectos de vida, quién puede ser entendido como ser viviente y quién vive o trata de vivir al otro lado de los modos de inteligibilidad establecidos.

\section{DEL CUERPO AL SUJETO. VULNERABILIDAD Y PRECARIDAD. EL SUJETO OPACO}

Foucault parte de una concepción reticular del poder, donde este se piensa de forma relacional, en tanto es ejercido bajo múltiples formas y direcciones. Así, el poder no es pensado como un fenómeno de dominación homogéneo de un individuo, grupo o clase sobre otros. Según él el poder "no es algo que se divide entre los que lo detentan como propiedad exclusiva y los que no lo tienen y lo sufren (...). Nunca está localizado aquí o allí, nunca está en las manos de alguien, nunca es apropiado como una riqueza o un bien”. Por tanto, su interés teórico radica en pensar el poder, en términos de las sujeciones múltiples, subrepticias, que tienen lugar y funcionan dentro del cuerpo social que, a la vez que sujetan al sujeto, lo constituyen socialmente. Su propuesta de estudiar el poder consiste en pensarlo como algo que circula y que ubica al individuo tanto en la condición de sufrir el poder como de ejercerlo, de modo que "el poder no se aplica a los individuos, sino que transita a través de los individuos.”(Foucault, 1992: 30-32).

Esta perspectiva reticular del poder, nos ofrece un buen marco para pensar este en relación con los actos performativos, dado que el poder transita a través de las acciones 
y los discursos de los sujetos, ubicándolos, en determinadas circunstancias, como víctimas del poder y, en otras, como sus agentes. De este modo, el devenir sujeto para Foucault supone un poder regulador, que vigila y castiga, labrando al sujeto de acuerdo con las reglamentaciones imperantes en una sociedad, pero que además le otorga existencia y le abre el camino de la subjetivación, a partir de su misma reglamentación. De aquí se desprende la concepción de sujeto de Butler, entendido como proceso en el que un individuo se vuelve sujeto a partir de su sometimiento a las reglamentaciones del poder, en términos tanto de sujeción como de subjetivación.

Por tanto, una de las cuestiones centrales respecto a la performatividad de género es considerar su vinculación con el poder. El hecho de que las actuaciones de género se sostienen a través de actos y gestos cotidianos no ignora el que la performatividad esté sometida a la retícula del poder, tal como lo entendió Foucault. La performatividad tiene que ver con "quién" puede ser producido como un sujeto reconocible, un sujeto que está viviendo, cuya vida vale la pena proteger y cuya vida, cuando se pierde, vale la pena lamentar. La vida precaria caracteriza a aquellas vidas que no están cualificadas como reconocibles, legibles o dignas de despertar sentimiento. Y de esta forma, "la precaridad es la rúbrica que une a las mujeres, los queers, los transexuales, los pobres y las personas sin Estado", como enumera Butler.

En la entrevista ya mencionada con Costera y Prins, Butler responde a la pregunta de por qué no utiliza la noción de "actor" como lo hacen B. Latour y D. Haraway que la prefieren a la noción (humanista) de "sujeto":

“Aun así, creo que existen razones para trabajar con la noción de sujeto, razones que tienen que ver con el modo por el cual éste está relacionado al legado del humanismo. Me gustaría sugerir también que la noción de sujeto carga con ella una duplicidad que es crucial enfatizar: el sujeto es aquel del que se supone del que "surge" la agencia, pero el sujeto es también aquel que está sometido a un conjunto de reglas que lo preceden. Este segundo sentido funciona a contrapelo de la concepción humanista de un self autónomo o de un actor humano firmemente enraizado. En verdad, la palabra "actor" tiene una resonancia teatral que sería muy difícil adoptar en mi trabajo, debido a la tendencia de leer "performatividad" como un proyecto goffmanesco de colocar una máscara y escoger representar un papel. Prefiero trabajar el legado del humanismo contra el mismo.”

En mi opinión queda claro que, después de haber realizado la crítica al sujeto de la modernidad, en la que tuvieron un carácter muy destacado algunas teóricas feministas, se facilita la posibilidad de un nuevo modelo de sujeto, cuya primera característica es la del embodiment, traducido como in-corporación, en-carnación: el sujeto está encarnado, in-cardinado, y, por tanto es un sujeto con marca de género o generizado, es un sujeto situado. Es decir, no es que haya muerto el sujeto sino que tenemos que estar reconstruyéndolo, re-significándolo permanentemente, como afirma la autora. En este sentido su obra, que parte de la deconstrucción del sujeto de la 
modernidad, o del humanismo como ella prefiere llamarlo, no prescinde del sujeto sino que lo resignifica. Lo que Butler parece proponer no es la muerte del sujeto, sino "una re-inscripción foucaultiana del sujeto, un esfuerzo por re-situar el sujeto como un lugar de resignificación.” El sujeto no es ni un fundamento ni un producto, sino la posibilidad permanente de un cierto proceso de resignificación, que es desviado y obstaculizado por medio de otros mecanismos de poder, pero que constituye la propia posibilidad del poder de ser reelaborado, porque si el poder constituye al sujeto, ese poder no desaparece en el momento en que el sujeto se construye, ya que el sujeto no está nunca totalmente construido. De ahí que en sus últimas obras Butler introduzca la idea del "sujeto opaco". En Dar cuenta de sí mismo, (Butler, 2009) el sujeto, y esto no es nuevo en ella, no es su propio fundamento porque nace en un contexto que se encuentra ya establecido y cuyo origen no puede ni siquiera recordar. Por eso el sujeto no nos puede narrar su vida ya que siempre habrá un principio que se le escapa y, si Butler habla de "dar cuenta de sí mismo" es admitiendo todas esas limitaciones. El sujeto aparece ya en un entramado de normas morales y, frente a la idea de Adorno de que el yo debe apropiarse vitalmente de esas normas morales, Butler cree que son las propias normas las que disponen el lugar para un sujeto, es decir, debemos preguntarnos de qué forma la moral produce al sujeto. El sujeto no es autotransparente, es opaco, porque Butler lo concibe como un ser relacional "cuyas relaciones iniciales y primarias no están siempre al alcance del conocimiento consciente". El sujeto es precario porque toda vida es precaria y está sometido a la interpelación del Otro. En palabras de Butler, "el yo no puede dar cuenta adecuada y definitiva de sí mismo porque es incapaz de volver a la escena de la interpelación que lo ha instaurado ni relatar todas las dimensiones retóricas de la estructura de interpelación en la cual tiene lugar ese dar cuenta de sí”.

Ya en Marcos de guerra (Butler, 2010) la autora nos introduce en una nueva problemática. Empieza por insistir en la precariedad (precariousness) de toda vida. Las vidas son precarias por definición, pueden ser eliminadas de modo voluntario o accidental, su persistencia no está garantizada. Junto a la precariedad, Butler crea una noción específicamente política: la "precaridad" (precarity) con la que designa "esa condición políticamente inducida en la que ciertas poblaciones adolecen de falta de redes de apoyo sociales y económicas y están diferencialmente más expuestas a los daños, la violencia y la muerte”. Tanto la precariedad como la precaridad son conceptos que se entrecruzan. La precariedad es consustancial a todas las vidas, la precaridad no. Existen vidas vivibles y vidas que no lo son, vidas que pueden ser lamentadas y otras que no. Son los marcos y las normas de una sociedad los que dibujan la separación entre unas y otras. Esto ocurre sobre todo en las guerras, pero también con la inmigración, el racismo, la pobreza. Toda vida es precaria por definición, pero eso no es lo mismo que decir que toda vida pueda ser vivible. El que toda vida sea precaria quiere decir que la vida siempre surge y se sostiene en el marco de unas condiciones de vida. "No podemos reconocer fácilmente la vida fuera de los marcos en los que esta es dada y dichos marcos no sólo estructuran la manera cómo llegamos a conocer e identificar la vida sino que además constituyen unas condiciones sostenedoras para esa misma vida.” (Butler, 2010: 43-44) De ahí que el concepto clave para Butler en esta cuestión sea el de vulnerabilidad. En su libro anterior, Vida 
precaria, afirmaba: "La violencia es una pequeña muestra del peor orden posible, un modo terrorífico de exponer el carácter vulnerable del hombre con respecto a otros seres humanos, un modo por el que la vida misma puede ser eliminada por la acción deliberada de otro."

Es evidente que todos vivimos con esa particular vulnerabilidad, una vulnerabilidad ante el otro que forma parte de la vida corporal, una vulnerabilidad ante esos súbitos accesos venidos de otra parte y que no podemos prevenir. Sin embargo, esta vulnerabilidad se exacerba bajo ciertas condiciones sociales y políticas. La autora habla de la aceptación de "una vulnerabilidad que sirva de base a una comprensión de nuestra comunidad", lo que podría llevarnos a convivir sin llegar a extremos como la guerra. Todo lo anterior lleva a Butler a un propósito claro: la construcción de una ontología social del cuerpo.

"Sin embargo, mi propósito es afirmar que, si queremos ampliar las reivindicaciones sociales y políticas respecto a los derechos a la protección, la persistencia y la prosperidad, antes tenemos que apoyarnos en una nueva ontología corporal que implique repensar la precariedad, la vulnerabilidad, la dañabilidad, la interdependencia, la exposición, la persistencia corporal, el deseo, el trabajo y las reivindicaciones respecto al lenguaje y a la pertenencia social. ...El "ser" del cuerpo al que se refiere esta ontología es un ser que siempre está entregado a otros: a normas, a organizaciones sociales y políticas que se han desarrollado históricamente con el fin de maximizar la precariedad para unos y de minimizarla para otros. No es posible definir primero la ontología del cuerpo y referirnos después a las significaciones sociales que asume el cuerpo. Antes bien, ser un cuerpo es estar expuesto a un modelado y a una forma de carácter social, y eso es lo que hace que la ontología del cuerpo sea una ontología social” (Butler, 2010: 15)

Ahora bien esta ontología nunca podría constituirse como una "ontología del individualismo", ya que esta sería, en definitiva, el cimiento de la teoría liberal que ella rechaza radicalmente. Según Butler la autoconservación spinoziana tiene una clara resonancia individualista. Para esta autora la autoconservación no es la meta más alta, ya que únicamente privilegia la asocialidad del sujeto por encima de su carácter necesariamente relacional.

En Vida precaria, Butler explica que el gobierno de Bush dejó patente el hecho de que la vida de los muertos en las Torres Gemelas eran vidas dignas de ser lamentadas, mientras que las vidas de aquellos que murieron a causa de la invasión de Afganistán y de Irak no lo eran. Creo que esto se puede sostener dentro de esa concepción que ella misma explica de los "marcos de guerra". Sin embargo, considero que también las vidas perdidas de los terroristas pueden haber sido lamentadas por el entramado familiar y social al que estos pertenecían, y ello no les hace menos criminales. Lo que me parece cierto es que, en todo caso, las vidas surgidas en la precaridad, las vidas "invivibles" forman parte de un marco epistemológico que nos hace aprehender lo que 
ocurre de un modo sesgado. Y esto depende de la consideración que tenemos del cuerpo.

\begin{abstract}
"El cuerpo supone mortalidad, vulnerabilidad, praxis: la piel y la carne nos exponen a la mirada de los otros, pero también al contacto y a la violencia, y también son cuerpos los que nos ponen en peligro de convertirnos en agentes e instrumento de todo esto. Aunque luchemos por los derechos sobre nuestros propios cuerpos, los cuerpos por los que luchamos nunca son lo suficientemente nuestros. El cuerpo tiene una dimensión invariablemente pública. Constituido en la esfera pública como un fenómeno social, mi cuerpo es y no es mío. Entregado desde el comienzo al mundo de los otros, el cuerpo lleva sus huellas, está formado en el crisol de la vida social; sólo más tarde, y no sin alguna duda, puedo reclamar mi cuerpo como propio.” (Butler, 2004: 52)
\end{abstract}

Como hemos visto, los cuerpos si bien son todos precarios y vulnerables, no están todos envueltos en la precaridad. A esos cuerpos o a esas vidas se refiere en Marcos de Guerra al hablar de vidas que son lamentadas:

“Esta distribución diferencial de la precariedad es, a la vez, una cuestión material y perceptual, puesto que aquellos cuyas vidas no se «consideran » susceptibles de ser lloradas, y, por ende, de ser valiosas, están hechos para soportar la carga del hambre, del infraempleo, de la falta de emancipación jurídica y de la exposición diferencial a la violencia y a la muerte.” (Butler, 2010: 45)

\title{
5. ¿ES POSIBLE EL FEMINISMO SIN LA TEORÍA DEL PATRIARCADO? RESISTENCIA (¿LUCHA?) Y NO VICTIMIZACIÓN. LA NECESIDAD DE UNA POLÍTICA FEMINISTA
}

Como hemos visto, Butler ha ido pasando del cuerpo como proceso de materalización y de performatividad a la vida (vivible o invivible) y luego al sujeto (opaco). Si bien es cierto que es significativa la revisión de conceptos como construcción, performatividad y proceso de materialización, su objetivo de construir una ontología social del cuerpo peca de un notable grado de abstracción. ¿Por qué Butler se muestra tan reticente a dar ejemplos de las teorías de las que habla o escribe? Ella lo justifica diciendo que cuando se presentan teorías abstractas sobre algo como podría ser la abyección, después aparecen los ejemplos, y, a renglón seguido, los ejemplos se hacen normativos de todo el resto. Y sin embargo debe existir, creo yo, un proceso inverso: los ejemplos pueden ayudar a entender esa teoría. Butler, en sus primeras obras, cuando habla de lo abyecto siempre se refiere a lo que se escapa de la heteronormatividad de género y solo más tarde amplía su campo. Como ya he señalado anteriormente, vemos que, según ella la precaridad, es una rúbrica que une a las mujeres, los queers, los transexuales, los pobres y las personas sin Estado. Es cierto 
que, entendida en los términos que ella utiliza, la precaridad, "esa condición políticamente inducida en la que ciertas poblaciones adolecen de falta de redes de apoyo sociales y económicas y están diferencialmente más expuestas a los daños, la violencia y la muerte", afecta a todos los que nombra pero, en mi opinión, el feminismo debe elaborar una teoría que analice específicamente la opresión sufrida por las mujeres y, en consecuencia actuar contra ella, aunque pueda unirse a las luchas de todas las vidas sometidas a la precaridad. Ella misma dice:

"El feminismo tiene que reconocer la precariedad como una condición compartida, y ligarla a fuertes compromisos de igualdad, procurando una universalización de los derechos que intente abordar las necesidades humanas básicas y las condiciones para persistir y prosperar. Pero debe, ante todo, combatir la precaridad como condición políticamente inducida que provoca que la violencia que se ejerce sobre determinadas poblaciones, y dentro de estas sobre las mujeres, crezca exponencialmente." (Butler, 2010:46)

Es decir, que aunque Butler habla de "una universalización más enérgica de los derechos que intente abordar las necesidades humanas básicas", reconoce que las mujeres son las que tienen menos acceso a estos derechos y, por tanto, son más vulnerables a la "precaridad". ¿¿No tendríamos que preguntarnos por qué ocurre esto?

En El género en disputa Butler analiza la idea de un patriarcado universal. Según la autora, esta noción se basa en la creencia política de que debe haber una base común para el feminismo y de que puede fundarse en una identidad que aparentemente existe en todas las culturas, con frecuencia ligada a la idea de que la opresión de las mujeres posee una forma específica que puede reconocerse dentro de la estructura universal o hegemónica del patriarcado. Según nos dice, esta noción ha recibido numerosas críticas “en los últimos años” porque no tiene en cuenta el funcionamiento de la opresión de género en los contextos culturales concretos en los que se produce.

"Una vez examinados esos contextos diversos en el marco de dichas teorías, se han encontrado «ejemplos» o «ilustraciones» de un principio universal que se asume desde el principio. Esa manera de hacer teoría feminista ha sido cuestionada porque intenta colonizar y apropiarse de las culturas no occidentales para respaldar ideas de dominación muy occidentales, y también porque tiene tendencia a construir un «Tercer Mundo» o incluso un «Oriente», donde la opresión de género es sutilmente considerada como sintomática de una barbarie esencial, no occidental." ${ }^{3}$ (Butler, 2001:102)

3 Las cursivas son mías. Considero que este tipo de afirmaciones, aunque se hicieron en 1990, constituyen una descalificación inadmisible del trabajo de muchas feministas. 
Butler cree que, cuando el feminismo empieza a luchar contra la opresión racial y colonialista, comprende que debe luchar también contra la estrategia epistemológica colonizadora "que subordinaría diversas configuraciones de dominación bajo el epígrafe de una noción transcultural del patriarcado.” Esto sitúa a nuestra autora en posturas próximas a las de la feminista postcolonial Chandra T. Mohanty en su artículo "Bajo los ojos de Occidente" (luego revisado) y que, en su momento, apareció como el paradigma de las concepciones del feminismo postcolonial.

"La autojustificación de una ley represiva o subordinante casi siempre se fundamenta en un relato que narra cómo eran las cosas antes de la constitución de la ley, y cómo surgió la ley en su forma actual y necesaria. La invención de esos orígenes detalla una situación previa a la ley en un relato necesario y unilineal cuya culminación es la creación de la ley, y así la justifica. Así pues, el relato de los orígenes es una estrategia dentro de una narración que, al explicar una única historia autorizada sobre un pasado que ya no se puede recuperar, hace surgir la constitución de la ley como una inevitabilidad histórica. El hecho de aludir a una feminidad original o auténtica es un ideal nostálgico y limitado que se opone a la necesidad actual de analizar el género como una construcción cultural compleja.” (Mohanty, 2008a)

Sabemos que Mohanty escribió su artículo en 1984 y el libro de Butler apareció en 1990, por lo que suponemos que Butler conoce sus términos. Pero el concepto de patriarcado, como tantos otros universales, no es esa vaga idea que Butler describe. Cèlia Amorós ha planteado una teoría nominalista moderada del patriarcado por la que lo concibe como "un conjunto metaestable, de pactos, asimismo metaestables, entre los varones, por el cual se constituye el colectivo de estos como género-sexo, y. correlativamente, el de las mujeres.” Estos pactos son metaestables, fluidos y muy laxos. "El tipo de pacto que existió en las sociedades pastoriles semíticas poco tiene que ver con nuestra situación." "Este sistema de pactos de reconocimiento entre los varones, con sus formas de ejercicio del poder y de hegemonía, su ideología y sus mecanismos institucionales, no es que carezca de identidad sino que no se trata de una esencia” (Amorós, 2005:86). Este tipo de pactos que Amorós, basándose en la teoría de H. Hartmann explora, no implican una visión conspiratoria de la sociedad patriarcal. Es un fenómeno estructural y este tipo de fenómenos no son intencionales (Amorós, 2005:115). En los pactos patriarcales el objeto del pacto son las mujeres.

Del mismo modo, para Christine Delphy el concepto de patriarcado tiene un sentido analítico: se trata de un sistema y no de una serie de desgraciadas casualidades; pero también sintético, ya que es un sistema político. Implica, al mismo tiempo división y jerarquía y para ella la jerarquía es un rasgo del sistema tan importante como la división. Porque el patriarcado, antes que cualquier otra cosa, es heteronormativo. Como explicó Gayle Rubin (quien propuso el concepto de sistema sexo-género, como más ajustado, en su opinión, al de patriarcado), el tabú del incesto presupone el de la homosexualidad. Y el patriarcado no es solo causa de la opresión de las mujeres sino también de aquellos "humanos" que no entran dentro de la heteronormatividad. La 
lucha de los movimientos LGTB se entiende como otra lucha (no la misma, desde luego), junto a la lucha feminista, de los “raros” (queer) contra las normas patriarcales que los hacen quedarse en el campo de lo ab-yecto, para utilizar el término de Butler.

Es cierto también que utilizar acríticamente este concepto puede llevar a un feminismo que vea a las mujeres como víctimas, algo que rechazamos muchas. Para Butler hay que hablar de un feminismo no victimizante que insista en la capacidad que tienen las mujeres para resistir los modelos de género. Es cierto que el hecho de que surjamos en un entramado de normas que ya nos vienen dadas, no quiere decir que no podamos criticarlas o, en definitiva, resistir. Ella misma dice, en referencia a Foucault:

\begin{abstract}
"Muchos se preguntan sobre qué base Foucault establece la resistencia al poder. Lo que nos está diciendo es que en la práctica de la crítica nos formamos como sujetos, a través de la resistencia y el cuestionamiento (...) El propio sujeto se forma a través de la práctica de la crítica. Y, efectivamente, desde mi punto de vista, ciertas formas de crítica suponen un cuestionamiento de la inteligibilidad de las normas que nos constituyen como personas. Si yo soy interpelada por las autoridades existentes como ciudadana o como no ciudadana, como un género o a través de una categorización racial, debo luchar contra esta determinación social. Las normas establecen mi inteligibilidad social, las categorías a través de las cuales entiendo a la gente y a mí misma.”(Butler, 2008)
\end{abstract}

Es decir, no debemos admitir que el patriarcado nos convierta necesariamente en víctimas, porque podemos resistir y actuar contra el. No obstante, para ello es preciso partir de un concepto de patriarcado diferente a la falsa noción a la que Butler alude. Ya hemos visto que para ella el dominio de la ontología es un dominio regulado, de tal forma que lo que se produce dentro de él, lo que es excluido de él para que el dominio se constituya como tal, es un efecto del poder. Y lo performativo puede ser una de las formas por las cuales el discurso se hace operativo debido al poder. Pues bien, considero que el hecho de que el patriarcado sea desechado por ella constituye, sin lugar a dudas, un efecto del poder que intenta ilegitimar este concepto y que opera también sobre el pensamiento de Butler. Además nuestra autora utiliza, sobre todo en sus últimas obras, conceptos como liberalismo, nacionalismo, sionismo y otros igualmente problemáticos, sin empacho alguno.

Pienso que si no se tiene en cuenta este concepto, es imposible explicar hechos que el feminismo analiza y contra los que lucha: la violencia contra las mujeres, los feminicidios, la trata de mujeres, la feminización cada vez mayor de la pobreza.... Estoy totalmente de acuerdo con C. Mohanty cuando afirma en la revisión de su primer artículo ya citado, escrita en 2003:

"Son las mujeres y niñas del mundo, especialmente del Tercer Mundo / Sur, quienes llevan la carga más pesada de la globalización. Las mujeres y 
niñas pobres son quienes reciben el impacto más fuerte de la degradación de las condiciones ambientales, de las guerras, del hambre, de la privatización de servicios y la desregulación de los gobiernos, de la desintegración de los Estados de bienestar, de la reestructuración del trabajo remunerado y no remunerado, de la creciente vigilancia y encarcelamiento en las prisiones, $\mathrm{y}$ más. $\mathrm{Y}$ por esto es necesario el feminismo sin, y más allá de, las fronteras para tratar las injusticias del capitalismo global.” (Mohanty, 2008b)

En consecuencia, si Butler considera que para una ontología social del cuerpo hay que repensar la precariedad, la vulnerabilidad, la interdependencia, la exposición de los cuerpos y otros elementos más, no creo que sea posible llegar a ello sin destacar que el cuerpo de las mujeres está más expuesto que el de los varones a todos estos factores. Todos los cuerpos son precarios, y muchos de ellos se inscriben además en la precaridad, sea cual sea su género, pero el cuerpo de las mujeres sufre una mayor violencia, quizá porque, como la misma Butler dice,

“cada estado-nación quiere controlar la reproducción, todo el mundo está muy inquieto con la reproducción: los conservadores españoles dicen "no" al aborto, ¿por qué? Porque es a través del control del cuerpo de las mujeres como se logra la reproducción de la población y se hace posible reproducir la nación, la raza, la masculinidad.” (Butler, 2008)

Y todo esto no se puede comprender adecuadamente sin tener en cuenta la teoría del patriarcado.

Por esta razón, y aunque podría referirme a cualquiera de las formas de violencia contra las mujeres señaladas anteriormente, analizaré solo un hecho atroz que me parece ilustrativo de la complejidad que muchas cuestiones plantean para la teoría feminista. El 14 de Abril del año 2014 fueron secuestradas al menos 200 niñas en el ataque de un grupo armado a una escuela-residencia del noroeste de Nigeria. El asalto se produjo por la noche en la localidad de Chinook, en el estado de Borno, territorio en donde actúa el grupo radical islámico Boko Haram. Las niñas no han vuelto a sus familias e incluso fueron secuestradas otras 60 después.

En algunas redes sociales se ha mencionado que las feministas de izquierda no han dicho nada ante esto (¿se supone que porque son cómplices del terrorismo islámico?). Desde luego, Zillah Eisenstein escribió:

(Estas niñas) son increíbles peones en un mundo lleno de grotescas desigualdades misóginas y de voracidad capitalista. Nigeria sufre los excesos de la pobreza para muchos, mientras que el país sigue siendo el mayor productor de petróleo en África. Boko Haram sobrevive dentro de 
una circundante pobreza y bandolerismo. La gran riqueza junto a la miseria absoluta entran en connivencia con una horrible misoginia que define a las niñas y a sus cuerpos como parte del tráfico sexual.” ${ }^{4}$

Es cierto que se desarrolló una campaña internacional con el lema "BringBackOurGirls" a la que se sumaron gran número de personalidades. Algunas de las niñas que han podido escapar relataron que habían sido violadas, maltratadas y aterrorizadas, para ser utilizadas ahora como "moneda de cambio" por sus captores en las negociaciones con el gobierno de Nigeria.

La campaña a la que aludo recuerda desgraciadamente a los llamamientos del gobierno de Bush a liberar a las mujeres de Afganistán de los talibanes, dentro de lo que Eisenstein denominó “feminismo imperial neo-liberal” y que desembocó en la cruenta intervención militar del 2001 (Eisenstein, 2008:56). Ahora, en vez de "las mujeres de Bush", como las llama Eisenstein, aparecen Michelle Obama, David Cameron y Dolores de Cospedal entre los que se unieron a la campaña. Como parece que el gobierno nigeriano no puede (o no quiere) luchar contra esta situación, las fuerzas militares de Estados Unidos, británicas, francesas y de otros estados han aparecido en Nigeria, quizá para no marcharse, aunque su propósito declarado fuera buscar a las niñas. No olvidemos que Nigeria es uno de los países más ricos de África; actualmente el primer productor de petróleo del continente, transformándose en la primera economía africana, por delante de Suráfrica. Pese a ello, la inmensa mayoría de la población vive en la miseria. Y se ha hablado muy poco en España de que las primeras manifestaciones realizadas en Abuya, la capital del país, fueron reprimidas por la policía y ello, según la versión del presidente Goodluck Jonathan, porque los que pedían la liberación de las niñas debían dirigirse al grupo terrorista y no al Gobierno nigeriano.

De momento los drones enviados por EE.UU. hacia Chad y Nigeria para esa "búsqueda" no han encontrado nada y seguramente sirven para otros propósitos menos loables. También el presidente de Francia, F. Hollande se reunió con el presidente nigeriano para ofrecerle ayuda. Francia, por supuesto, tiene intereses económicos en ese país.

Creo que el grupo terrorista Boko Haram, que enarbola el pretexto de que no hay que permitir que las mujeres sean educadas más que en el Corán y que se conviertan al Islam, idea que ha sido escogida como el único motivo por muchos "occidentales", en realidad secuestra a estas niñas para casarlas con sus jóvenes y míseros combatientes; $\mathrm{y}$, en último caso, para intercambiarlas por prisioneros o venderlas a las redes de tráfico de mujeres que son muy activas en Nigeria. Es decir, para ellos las mujeres son un recurso económico y sexual. Y, sobre todo, no olvidemos que, además, son futuras

${ }^{4}$ EISENSTEIN, Z., “An Alert: Capital is Intersectional; Radicalizing Piketty’s Inequality”, en http://thefeministwire.com/2014/05/alert-capital-intersectional-radicalizing-pikettys-inequality/, May 2014. La traducción es mía. 
madres de guerrilleros que relevarán a los milicianos actuales. Las niñas y sus cuerpos forman parte del tráfico sexual, como dice Z. Eisenstein y Mohanty. La misma Butler señala: "Porque es a través del control del cuerpo de las mujeres como se logra la reproducción de la población y se hace posible reproducir la nación, la raza, la masculinidad."

Además de todo lo dicho anteriormente, las mujeres sirven, también, como una instancia de legitimación de las guerras:

"En noviembre de 2012, la feminista Aminata Traoré firmaba junto a distintas personalidades malienses un manifiesto en el que denunciaba la instrumentalización de la violencia contra las mujeres para legitimar las guerras y la injerencia en su país. Ese mismo año la feminista nigeriana Amina Mama señalaba la necesidad de problematizar "la retórica omnipresente occidental de 'terror' que justifica y sostiene la expansión militar continuada en nombre de un discurso eminentemente norteamericano centrado en la doctrina de la seguridad". ${ }^{5}$

Está claro que para el feminismo es absolutamente repudiable el terrorismo de Boko Haram. Sin embargo, y como dice la profesora de la Universidad de Granada Soledad Vieitez,
"vemos como en estos días muchas personas reconocibles de todos los ámbitos de la política se hacen la foto, sin hacer la más mínima autocrítica de hasta qué punto las políticas económicas de sus propios países han contribuido a polarizar a estos grupos en Nigeria o en Somalia hasta alcanzar esta situación. De fondo hay numerosos objetivos geoestratégicos de primera magnitud."6

En definitiva, el repudio por el secuestro de las niñas nigerianas es algo que es necesario efectuar siempre. Pero es difícil hacer el análisis de una situación tan compleja quedándonos solo en una campaña por muy "viral” que sea. Los terroristas de Boko Haram ni se inmutan por ello. Sin embargo, también existe el peligro de utilizar a estas niñas como pretexto para una intervención neoliberal "humanitaria"7 . Por ello, el feminismo debe analizar con sumo cuidado situaciones como las ya descritas, porque el poder económico y político patriarcal sabe muy bien cómo aprovecharlas

\footnotetext{
${ }^{5}$ Sánchez Aroca, I. (2014) “Nigeria: las mujeres como pretexto en las intervenciones militares”,Madrid 29 de Mayo de 2014, www.diagonalperiodico.net/global/22938.

${ }^{6}$ Tomado del artículo de Sánchez-Aroca ya citado.

${ }^{7}$ R.Reeve, Director del Oxford Research Group's Sustainable Security Programme, nada sospechoso de complicidades terroristas, escribe sobre este peligro. "Boko Haram: completing the circle of liberal interventionism?”, https://www.opendemocracy.net/opensecurity/richard.reeve, 29 May 2014.
} 
para encubrir otras crueldades contra las mujeres realizadas en el propio seno de las sociedades que envían armas y soldados para "buscar" a las niñas. ${ }^{8}$

Volviendo a los "pactos patriarcales", el espacio en el que se realizan es el de la política. Por ello y sin rechazar la posibilidad de una ontología social de cuerpo, creo que es fundamental definir una política feminista, necesaria porque, como dice Amorós, "tan solo las radicales aspiraciones feministas de igualdad podrán lograr la desmitificación y la verdadera racionalización de la política.” Hoy, hasta los intelectuales conservadores admiten que las políticas neoliberales de la globalización no han hecho más que aumentar la desigualdad y, por ende, también la desigualdad entre mujeres y varones. Hay que tener en cuenta que "la igualdad no es un hecho; es un concepto regulativo político, un concepto ético y un valor" y, por tanto, se tiene que construir. (Amorós, 2005:288) Es decir, aunque intentemos elaborar una ontología social del cuerpo, tendremos que actuar en el plano político, analizando cuidadosamente y reivindicando las exigencias de las mujeres en el mundo globalizado, siempre teniendo en cuenta la teoría del patriarcado, a riesgo de que, si no lo hacemos, nuestros análisis y nuestras conclusiones sean inadecuados.

Otra cuestión que atañe directamente al cuerpo de las mujeres es la de la lucha por derogar la actual Ley de la interrupción voluntaria del embarazo en España y sustituirla por una ley de plazos. Butler en Marcos de Guerra habla de que tenemos que estar a favor del derecho a la vida, pero a una vida "vivible". "La cuestión no es si determinado ser es vivo o no, ni si tiene o no estatus de persona, sino si las condiciones sociales de su persistencia y prosperidad son o no posibles.” Y sigue,

"De manera parecida, la decisión de abortar un feto puede estar perfectamente fundamentada en la idea de que faltan las formas de apoyo social y económico necesarias para que esa vida sea "vivible" (Butler, 2010: 38-43).

Pues bien, Amorós analiza mucho más certeramente este tema en su último libro. "Tienen derecho a la vida las personas que tienen vida, pero para tenerla requieren el concurso consciente y libre de quien da la vida humana.” Y estas son las mujeres,

8“ ¿Por qué les preocupan estas pobres muchachas, y no las 683.000 mujeres estadounidenses, en su mayoría negras y pobres, que son raptadas y/o violadas cada año? El 83\% de las niñas en edades entre 12 a 16 años son víctimas de la agresión sexual, al igual que otros 800.000 menores de 10 años, sin que hubiese alguna campaña para atajar este vergonzoso problema, allí y en otros países del mundo. Desde Europa, los mandatarios ricos y blancos que ahogan a los exiliados africanos en sus mares son capaces de colgar en internet sus fotos de solidaridad. ¡Embusteros! Están defendiendo sus propios intereses siempre infames, ayer con el tema del burka de las afganas y ahora se aprovechan de la tragedia de estas niñas”. Nazanín Armanian “Estados Unidos: ¿intenciones altruistas en el recate de las niñas nigerianas?”, en http://blogs.publico.es/puntoyseguido, 11 de Mayo de 2014. 
sujetos de derecho de su vida, una vida a la que dan sentido ellas mismas, quienes deben ser las intérpretes de su situación y elegir en consecuencia. Para que "la vida humana se realice plenamente tiene que ser una vida concebida por la madre en su mente y en su vientre al mismo tiempo ya que, en caso contrario, será una vida mostrenca" "Proyectar conscientemente es lo específicamente humano, concebir los hijos concebidos", dice la autora (Amorós, 2014:40). Pero todo ello hay que entenderlo en el marco de la crítica de la sabiduría salomónica como sabiduría patriarcal, "que adjudica al varón la transmisión de la carne y la palabra, mientras que a la mujer solo le reserva la primera”. En definitiva, sin apoyarnos en la teoría del patriarcado, no podremos explicar con justeza la postura del feminismo ante el aborto.

Desearía que estas reflexiones sirvieran para ser contrastadas con la aproximación crítica que he pretendido hacer a lo que Butler llama "una ontología social del cuerpo". Como ella misma dice: "No es posible definir primero la ontología del cuerpo y referirnos después a las significaciones sociales que asume el cuerpo" (Butler, 2010:15). Los cuerpos de las niñas y mujeres en todo el planeta son los que padecen las peores consecuencias de la globalización en sus diferentes formas de violencia patriarcal.

\section{REFERENCIAS BIBLIOGRÁFICAS}

AMORÓS, C., (1997): Tiempo de feminismo. Sobre feminismo, proyecto ilustrado y postmodernidad. Madrid, Cátedra.

AMORÓS, C., (2005): La gran diferencia y sus pequeñas consecuencias... para las luchas de las mujeres. Madrid, Cátedra.

AMORÓS, C., (2014): Salomón no era sabio. Madrid, Fundamentos.

BORDO, S., (1994): Unbearable Weight, Feminism, Western Culture and the Body. Oakland, University of California Press.

BUTLER, J., (2001): El género en disputa: el feminismo y la subversion de la identidad. Barcelona, Paidós.

BUTLER, J., (2003): Cuerpos que importan: sobre los límites materiales y discursivos del sexo. Barcelona, Paidós.

BUTLER, J., (2006): Vida Precaria; el poder del duelo y la violencia. Buenos Aires, Paidós. La primera edición en inglés fue publicada en Londres, Verso, 2004.

BUTLER, J., (2008): «Entrevista con Judith Butler: "el género es extramoral"» en Revista Barcelona Metrópolis [en línea], (Junio-Septiembre 2008).

BUTLER, J., (2009): Dar cuenta de sí mismo. Violencia ética y responsabilidad. Buenos Aires, Amorrortu Editores.

BUTLER, J., (2010): Marcos de guerra: las vidas lloradas. Barcelona, Paidós. La primera edición en inglés fue publicada en Londres, Verso, 2008. 
COSTERA, I., y BAUJKE, P. (1998): "How Bodies Come to Matter: An Interview with Judith Butler”. Signs, Vol. 23, nº 2, pp. 275-286.

EISENSTEIN, Z., (2008): Señuelos sexuales. Género, raza y guerra en la democracia imperial. Barcelona, Bellaterra.

FOUCAULT, M., (1968): Las palabras y las cosas: una arqueología de las ciencias humanas. Buenos Aires, Siglo XXI editores.

FOUCAULT, M., (1976): Vigilar y castigar. Nacimiento de la prisión. Buenos Aires, Siglo XXI editores.

FOUCAULT, M., (1977): Historia de la Sexualidad, vol. 1: La voluntad de saber. Buenos Aires, Siglo XXI editores.

FOUCAULT, M., (1986): Historia de la Sexualidad, vol. II: El uso de los placeres. Buenos Aires, Siglo XXI editores.

FOUCAULT, M., (1991): Saber y Verdad. Madrid, La Piqueta.

FOUCAULT, M., (1992): Microfísica del poder, Madrid, La Piqueta.

MOHANTY, C., (2008a): Bajo los ojos de Occidente. Feminismo académico y discursos coloniales. En Hernández, R., y Suárez, L., Descolonizando el feminismo: teorías y prácticas desde los márgenes, pp. 112-160, Madrid, Cátedra.

MOHANTY, C. (2008b): De vuelta a Bajo los ojos de Occidente: la solidaridad feminista a través de las luchas anticapitalistas. En Hernández, R., y Suárez, L., Descolonizando el feminismo: teorías y prácticas desde los márgenes, pp. 404-438, Madrid, Cátedra. 